\title{
ANALISIS TESKTUR TANAH, KANDUNGAN UNSUR HARA DAN TOTAL MIKROBA TANAH BEKAS PENAMBANG EMAS TANPA IZIN (PETI) DARI BEBERAPA KECAMATAN KABUPATEN KUANTAN SINGINGI
}

(Analysis of the texture, Nutrients Contents, and Total of Microbial Soil Post Gold Mining Area (PETI) from Some Sub-districts in Kuantan Singingi District)

\author{
SRI MULYANI ${ }^{1 *}$, SITI ZAHRAH ${ }^{1}$, SULHASWARDI ${ }^{1}$ \\ ${ }^{1}$ Program Studi Agroteknologi, Fakultas Pertanian, Universitas Islam Riau \\ Jl. Kaharuddin Nasution No. $113 \mathrm{Km} 11$ Perhentian Marpoyan, Pekanbaru, Riau \\ *Email: srimulyani@agr.uir.ac.id
}

\begin{abstract}
This unlicensed gold mining activity (PETI) can have a positive impact on the economy of the community, in the form of increased incomes so that it can improve the welfare of the community. However, besides having a positive impact, PETI's activities will harm the environment around the mining area. The negative impact caused by mining activities is environmental damage in the form of a decrease in land quality as indicated by a decrease in physical, chemical, and biological soil quality. The purpose of this study was to determine the texture, nutrient content, and the total of microbes in former PETI soils in sub-districts of the Kuantan Singingi Regency. The parameters observed were analysis of sand, dust, clay, soil pH, C-organic, $\mathrm{N}$-total, $\mathrm{P}_{2} \mathrm{O}_{5}, \mathrm{~K}_{2} \mathrm{O}$, interchangeable cations, CEC, a saturation of bases, Aluminum Saturation, and analysis of total soil microbes. The results showed that the Singingi sub-district, Central Kuantan sub-district, Sentoja sub-district, and Logas Tanah Darat sub-district has the texture of sand soil clay to sand, the content of $\mathrm{pH} \mathrm{H}_{2} \mathrm{O} 5,75-6,64$ is rather sour, C-Organic 0,07-0,26\%, Ca-dd 0,025-0,050 me/100g, Nitrogen-Total 0,02-0,03\%, Mg-dd 0,09-0,17 me/100g and CEC 1,39-2,11 me/100g with very low fertility criteria, C/N Ratio 3,50-8,67 with low to very low fertility criteria, K-dd content 0,24-0,31 with low criteria, Na-dd 0,08-1,19 me/100g with moderate to very high criteria, aluminum saturation is very high with wet saturation the fertility criteria are low. The total microbes in the Sub-district of Sentoja Raya and Logas Tanah Darat Sub-district are much higher than Singingi Sub-district and Central Kuantan Sub-district.
\end{abstract}

Keywords: PETI, Nutrients, Total Microbial

\section{PENDAHULUAN}

Kegiatan penambangan adalah salah satu kegiatan pemanfaatan sumberdaya alam. Salah satu contoh kegiatan penambangan ini adalah Penambangan Emas Tanpa Izin (PETI) di Riau khususnya di Kabupaten Kuantan Singingi. Kegiatan PETI dapat memberikan dampak buruk pada lingkungan sekitar lahan tambang. Dampak buruk yang ditimbulkan oleh kegiatan penambangan yaitu kerusakan lingkungan berupa penurunan kualitas lahan yang ditunjukkan dengan penurunan kualitas fisik, kimia dan biologi tanah (Maryani, 2007).

Kerusakan fisik pada lahan bekas tambang pada umumnya sebagai akibat dari proses pengupasan tanah pucuk dan tanah penutup (overburden), penimbunan dan pemadatan yang menggunakan alat berat sehingga struktur tanah menjadi rusak, sistem tata air dan aerasinya terganggu, laju penyerapan air kedalam tanah membutuhkan waktu yang lama dan berpotensi meningkatkan laju erosi. Kerusakan sifat kimia tanah bekas tambang karena kehilangan bahan organik, tercampur tanah pucuk dengan overburden, dan juga dapat menyebabkan terpaparnya pirit (FeS2) sehingga $\mathrm{pH}$ tanah rendah, kelarutan logam-logam berat meningkat. Kerusakan biologi tanah bekas tambang yaitu lahan mengalami penurunan populasi dan aktivitas mikroba serta fauna tanah yang secara tidak langsung mempengaruhi kehidupan tanaman dan berperan dalam dekomposisi serasah (Widyati, 2008).

Selain itu, Menurut hasil penelitian Nuraini et al., (2014) dampak negatif dari kegiatan penambangan emas yaitu terbentuknya lahan kritis berupa tanah bekas tambang emas yang tidak dapat berfungsi dengan baik dalam mendukung pertumbuhan tanaman.

Akibat aktivitas PETI yang menimbulkan dampak negatif yaitu bagi lahan yang dikelola masyarakat, maka diperlukan adanya penanganan khusus untuk menyikapi terjadinya kerusakan lahan agar tidak semakin 
parah dan dapat menimbulkan bencana alam yang merugikan lingkungan setempat, yakni dengan cara merehabilitasi lahan tersebut. Rehabilitasi lahan terdiri dari kegiatan reklamasi, yaitu suatu usaha untuk memperbaiki lahan yang rusak sebagai akibat dari kegiatan penambangan, agar dapat berfungsi secara optimal sesuai dengan kemampuannya, yang kemudian diikuti oleh kegiatan revegetasi. Kegiatan revegetasi merupakan kegiatan penanaman kembali di dalam suatu kawasan misalnya kawasan hutan yang rusak. Selanjutnya dilakukan kegiatan evaluasi terhadap kegiatan reklamasi dan revegetasi agar dapat diketahui tingkat keberhasilan yang telah dicapai (Putra, 2010). Sebelum dilakukan kegiatan rehabilitasi lahan perlu dilakuakn penilaian karakteristik lahan bekas tambang emas. Dari permasalahan diatas, maka perlu dilakukan penelitian "Analisis Kandungan Unsur Hara dan Total Mikrob Tanah Bekas Tambang Emas Tanpa Izin (PETI) dari beberapa Kecamatan Di Kabupaten Kuantan Singingi."

\section{BAHAN DAN METODE}

Penelitian ini dilaksanakan Kecamatan Singingi, Kecamatan Kuantan Tengah, Kecamatan Sentoja Raya dan Kecamatan Logas Tanah Darat. Analisis kandungan hara dilakukan di Laboratorium Central Plantation Services, Pekanbaru dan Analisis total Mikroba, di Laboratorium Tanah, Tanaman, Pupuk, Air Badan Pengembangan Penelitian dan Pengembangan Pertanian, Bogor. Penelitian ini telah dirangkai selama 4 bulan terhitung mulai bulan Agustus sampai dengan November 2019.

Bahan yang digunakan dalam penelitian ini adalah tanah dari masing-masing lokasi lahan bekas tambang emas dari Kecamatan Singingi, Kecamatan Kuantan Tengah, Kecamatan Sentoja Raya dan Kecamatan Logas Tanah Darat serta bahan-bahan yang digunakan untuk analisis di laboratorium. Alat yang digunakan dalam penelitian ini adalah GPS, parang, ring tanah (terbuat dari pipa paralon), cangkul, kantong plastik, phiband, timbangan biasa, timbangan digital, Peta lokasi sebaran lahan berkas tambang emas tanpa izin di beberapa kecamatan kabupaten Kuantan Singingi (mulyani, 2018), alat tulis, kamera digital dan alat-alat yang digunakan untuk analisis di laboratorium.

Penelitian ini dibagi menjadi 2 kegiatan, yaitu: 1) Pengambilan sampel tanah; 2) Analisis kandungan unsur hara dan analisis total mikrob pada tanah bekas tambang emas tanpa izin.

\section{Pengambilan Sampel Tanah Bekas PETI Di beberapa kecamatan di Kabupaten Kuantan Singingi}

Titik sampling dalam pengambilan contoh tanah berdasarkan pada Peta Studi Sebaran Lahan bekas Tambang Emas dan survei lokasi dengan bantuan GPS. Titik-titik sampling ditentukan dengan menggunakan metode Purposive Sampling yaitu Sampel tanah yang diambil hanya atas dasar pertimbangan penelitinya yang menganggap unsur-unsur yang dikehendaki telah ada dalam anggota sampel (Nasution, 2003).

Pengambilan contoh tanah di lapangan dilakukan dengan metode yang dikembangkan oleh Balai Penelitian Tanah (2006) yang telah dimodifikasi dengan cara sebagai berikut:

1. Menetapkan pusat (bagian plot bekas tambang emas) sebagai salah satu titik tetap dalam pengambilan contoh tanah pada masing-masing lokasi lahan bekas tambang emas

2. Menentukan tiga plot lainnya berdasarkan bentuk kontur tanah. Satu plot pada areal yang berkontur miring, dua plot pengambilan contoh tanah lainnya diletakkan pada bagian permukaan tanah yang lebih tinggi dan bagian permukaan tanah yang lebih rendah dari plot pada bagian pusat blok bekas tambang emas dengan jarak minimal $5 \mathrm{~m}$.

3. Pada areal berkontur datar, penentuan plot diletakkan secara sembarang dengan jarak minimal $5 \mathrm{~m}$ dari plot yang ada pada pusat blok bekas tambang emas, hal ini dilakukan karena pada permukaan tanah yang datar sifat tanahnya relatif tidak berbeda dalam satu hamparan yang homogen.

4. Kemudian permukaan tanah dibersihkan dari serasah dan kotoran-kotoran lainnya, kemudian ring yang terbuat dari pipa paralon (tinggi $=30 \mathrm{~cm}$ ) diletakkan tegak lurus dengan permukaan tanah (bagian ring yang tajam berada di bawah).

5. Setelah itu, ring tanah ditekan ke dalam tanah hingga tertanam keseluruhan dan bagian paling atas ring rata dengan permukaan tanah kemudian permukaan ring bagian atas ditutup untuk menghindari masuknya serpihan-serpihan tanah atau kotoran-kotoran lainnya ke dalam ring.

6. Ring yang sudah tertanam dicongkel untuk mengeluarkan ring yang telah berisi contoh tanah dari dalam tanah, kemudian tanah bagian bawahnya diiris menggunakan parang untuk meratakan permukaan bagian bawahnya. Setelah itu, contoh tanah yang ada di dalam ring 
dikeluarkan dari ring dan dimasukkan dalam kantong pastik.

7. Contoh tanah yang dianalisis dalam penelitian ini merupakan contoh tanah komposit hasil gabungan dari keempat plot pengambilan contoh tanah.

8. Persiapan contoh tanah di laboratorium yaitu tanah komposit dari lapangan segera dikering udarakan pada suhu ruangan tertutup tanpa ada sinar matahari untuk selanjutnya dilakukan analisis tanah.

Tahap Analisis Testur Tanah, Kandungan Unsur Hara dan Analisis Total Mikrob

\begin{abstract}
Tanah Bekas PETI dari Beberapa Kecamatan di Kabupaten Kuantan Singingi Analisis Kandungan Unsur Hara Tanah bekas PETI

Penilaian hasil pengamatan analisis tanah PETI berdasarkan kriteria Balai Penelitian Tanah (2009). Penilaian hasil analisis tanah menurut Parameter pengamatan untuk analisis tanah terdiri dari Pengamatan sifat kimia tanah dan kandungan logam berat pada tanah bekas PETI. Parameter pengamatan, metode analisis dan alat ukur yang digunakan disajikan pada Tabel 1. Data yang diperoleh disajikan dalam bentuk tabel dan gambar.
\end{abstract}

Tabel 1. Parameter pengamatan, metode analisis dan alat ukur untuk analisis tanah bekas tambang emas

\begin{tabular}{|c|}
\hline \multirow[t]{2}{*}{ Parameter Pengamatan } \\
\hline \\
\hline 1. Pasir $(\%)$ \\
\hline 2. Debu (\%) \\
\hline 3. Liat (\%) \\
\hline Sifat kimia tanah \\
\hline 1. $\mathrm{pH} \mathrm{H}_{2} \mathrm{O}$ \\
\hline 2. C-Organik (\%) \\
\hline 3. Nitrogen-Total (\%) \\
\hline 4. $\mathrm{P}_{2} \mathrm{O}_{5}(\mathrm{ppm})$ \\
\hline 5. Susunan Kation \\
\hline - Ca-dd (me/100g) \\
\hline - $\quad \mathrm{Mg}-\mathrm{dd}(\mathrm{me} / 100 \mathrm{~g})$ \\
\hline - $\quad \mathrm{K}-\mathrm{dd}(\mathrm{me} / 100 \mathrm{~g})$ \\
\hline - $\quad \mathrm{Na}-\mathrm{dd}(\mathrm{me} / 100 \mathrm{~g})$ \\
\hline 6. KTK \\
\hline 7. Kejenuhan basa (\%) \\
\hline 8. Kejenuhan Aluminium (\%) \\
\hline
\end{tabular}
untuk analisis total mikrob merujuk pada Hastuti \& Ginting (2007), metodenya adalah metode cawan hitung dengan medianya berupa Nutrient agar. Data yang diperoleh disajikan dalam bentuk tabel dan gambar.

Penghitungan jumlah populasi mikrob dilakukan dengan metode tuang (pour plate count) yang diawali dengan isolasi mikrob menggunakan metode seri pengenceran (dilution method) sampai tingkat tertentu. Pengenceran dilakukan secara bertingkat dengan cara sebagai berikut:

1. Timbang $10 \mathrm{~g}$ contoh tanah, kemudian disuspensikan ke dalam $90 \mathrm{ml}$ larutan fisiologis (8.5 g NaCl/1 liter aquades) sehingga diperoleh seri pengenceran $10^{-1}$.

2. Satu $\mathrm{ml}$ larutan dengan seri pengenceran $10^{-1}$ kemudian ditambahkan ke dalam $9 \mathrm{ml}$

Pipet (ayakan)

Pipet (ayakan)

Pipet (ayakan)

Elektroda ( $\mathrm{pH}$ meter)

Walkley and Black

Kjeldhahl (Titrasi)

Ekstrak Bray I ((Spectrophotometer)

Ekstrak $\mathrm{NH}_{4} \mathrm{OAc} \mathrm{N} \mathrm{pH} 7.0$ (AAS)

Ekstrak $\mathrm{NH}_{4} \mathrm{OAc} \mathrm{N} \mathrm{pH} 7.0$ (AAS)

Ekstrak $\mathrm{NH}_{4} \mathrm{OAc} \mathrm{N} \mathrm{pH} 7.0$ (Flamephotometer)

Ekstrak $\mathrm{NH}_{4} \mathrm{OAc} \mathrm{N} \mathrm{pH} 7.0$ (Flamephotometer)

Ekstrak $\mathrm{NH}_{4} \mathrm{OAc} \mathrm{N} \mathrm{pH} 7.0$ (Titrasi)

Perhitungan $=\frac{(m e(C a+M g+K+N a)-d d}{K T K T o t a l} \times 100 \%$

Perhitungan $=\frac{(\text { me Al-dd })}{\text { KTK Efektif }} \times 100 \%$

larutan fisiologis untuk memperoleh pengenceran $10^{-2}$, demikian seterusnya sampai dengan pengenceran yang dikehendaki.

3. Seri pengenceran yang digunakan untuk menetapkan masing-masing parameter berbeda.

4. Tingkat pengenceran untuk parameter populasi mikrob merujuk pada Widyastuti dan Anas (2013) yaitu menggunakan pengenceran $10^{-6}$ dan $10^{-7}$

5. Setelah seri pengenceran dilakukan, sebanyak $1 \mathrm{ml}$ larutan dari masing-masing seri pengenceran untuk diisolasikan pada media biak Nutrient agar yang sesuai dengan metode sebar (spread plate).

6. Selanjutnya dilakukan inkubasi di dalam inkubator selama 3-5 hari dengan suhu $28^{\circ} \mathrm{C}-31^{\circ} \mathrm{C}$.

Setelah masa inkubasi, mikrob yang tumbuh pada cawan petri kemudian dihitung menggunakan metode yang merujuk pada 
Napitupulu (2012) dengan persyaratan sebagai berikut :

1. Satu koloni dihitung satu koloni

2. Dua koloni yang bertumpuk dihitung satu koloni

3. Beberapa koloni yang berhubungan dihitung satu koloni

4. Dua koloni yang berhimpit dan masih dapat dibedakan dihitung dua koloni

5. Koloni yang terlalu besar (lebih dari setengah luas cawan petri) tidak dihitung dan

6. Koloni yang besar kurang dari setengah luas cawan dihitung satu koloni. berikut:

Rumus Perhitungan total mikrob sebagai

Total Populasi cfu $\mathrm{g}^{-1}$ tanah kering $=$

\begin{aligned} & \multicolumn{2}{c}{ (jumlah koloni $) \times(f p)$} \\ Keterangan: & \\ $\mathrm{Fp} \quad= &$ Faktor pengenceran \\ & pada cawan petri \\ & yang koloninya \\ & dihitung \\ $\mathrm{bk} \quad &$ Berat kering contoh \\ & tanah $(\mathrm{g})=$ berat \\ & basah $\times(1-$ kadar air $)\end{aligned}$

\section{HASIL DAN PEMBAHASAN}

\author{
Tesktur Tanah Bekas Tambang Emas \\ Tanpa Izin
}

Berdasarkan hasil pengamatan pada lahan bekas PETI pada empat kecamatan yaitu Kecamatan Singingi, Kecamatan Kuantan Tengah, Kecamatan Sentoja Raya dan Kecamatan Logas Tanah Darat Kabupaten Kuantan Singingi menunjukan bahwa tanah bekas PETI memiliki tekstur kasar yaitu pasir berlempung sampai pasir (Tabel 2).

Tekstur tanah yang baik untuk pertumbuhan tanamaan adalah tanah lempung berdebu Karena perbandingan pasir, debu dan liat berada pada jumlah berimbang. Sedangkan pada lahan bekas tambang emas lebih banyak mengandung pasir sehingga tanah bersifat sangat poros dan mudah tererosi, unsur hara mudah tercuci serta kurang mengikat unsur hara yang ditunjukan dengan rendahnya KTK tanah (Tabel 2). Menurut Hardjowigeno (2003) tekstur tanah yang ideal untuk pertumbuhan tanaman adalah lempung berdebu. Tanah tersebut mengandung bahan organik $5 \%$, udara $25 \%$ dan air $25 \%$.

Tabel 2. Tekstur tanah lahan bekas tambang emas tanpa izin

\begin{tabular}{lcccc}
\hline \multirow{2}{*}{ Lokasi Pengamatan } & \multicolumn{3}{c}{ Fraksi Tanah } & \multirow{2}{*}{ Tekstur Tanah } \\
\cline { 2 - 4 } & Pasir (\%) & Liat (\%) & Debu (\%) & Pasir Berlempung \\
\hline Kec. Singingi & 87,4 & 5,6 & 7,0 & Pasir \\
Kec. Kuantan Tengah & 90,4 & 4,8 & 4,8 & Pasir \\
Kec. Sentoja Raya & 91,2 & 4,8 & 4,0 & Pasir \\
Kec. Logas Tanah Darat & 90,2 & 4,2 & 5,6 & \\
\hline
\end{tabular}

Kandungan Unsur Hara pada Tanah Bekas Tambang Emas Tanpa Izin

Berdasarkan hasil pengamatan pada lahan bekas PETI pada empat kecamatan yaitu Kecamatan Singingi, Kecamatan Kuantan Tengah, Kecamatan Sentoja Raya dan Kecamatan Logas Tanah Darat Kabupaten Kuantan Singingi menunjukan bahwa tanah bekas PETI memiliki kandungan $\mathrm{pH} \mathrm{H}_{2} \mathrm{O}$ Tanah tergolong kesuburan sangat masam, C-Organik (\%) dengan kriteria kesuburan sangat rendah, Nitrogen-Total (\%) dengan kriteria kesuburan sangat rendah dan $\mathrm{C} / \mathrm{N}$ Ratio dengan kriteria kesuburan rendah sampai dengan sangat rendah, kandungan $\mathrm{K}$ dd dengan kriteria rendah, Ca-dd dengan kriteria kesuburan sangat rendah, kandungan Mg-dd dengan kriteria kesuburan sangat rendah, Na-dd dengan kriteria sedang dan sangat tinggi, Nilai KTK dengan kriteria kesuburan sangat rendah, kejenuhan aluminium sangat tinggi dengan kejenuhan basah kriteria kesuburannya rendah (Tabel 3) sehingga tanah ini tidak subur jika digunakan sebagai media pertumbuhan tanaman.

Sangat rendahnya tingkat kesuburan tanah pada lahan bekas PETI di kabupaten Kuantan Sengingi sebagai akibat dari kegiatan pertambangan yang merusak tanah dan lingkungan. Berdasarkan wawancara langsung kepada masyarakat dan temuan di lapangan bahwa kegiatan pertambangan emas tanpa izin dilakukan di daratan yang dekat dengan daerah aliran sungai. Hal tersebut dilakukan untuk memudahkan kegiatan para penambang dalam proses pencarian emas. Air sungai digunakan untuk menyemprot tanah yang rata-rata bertebing menggunakan mesin berkekuatan 5,5 PK/unit untuk menambang emas, selanjutnya material tersebut diolah ke dalam "sluice box" yang kemudian mineralmineral berat yang tertinggal dalam sluice box di dulang untuk memperoleh emas. 
Tabel 3. Kriteria Kesuburan Tanah pada tanah bekas tambang emas di beberapa kecamatan Kab. Kuantan Singingi

\begin{tabular}{|c|c|c|c|c|}
\hline \multirow[b]{2}{*}{ Parameter Pengamatan } & \multicolumn{4}{|c|}{ Lokasi Pengamatan } \\
\hline & Kec. Singingi & $\begin{array}{c}\text { Kec. Kuantan } \\
\text { Tengah }\end{array}$ & $\begin{array}{c}\text { Kec. Sentoja } \\
\text { Raya }\end{array}$ & $\begin{array}{l}\text { Kec. Logas } \\
\text { Tanah Darat }\end{array}$ \\
\hline 1. $\mathrm{pH} \mathrm{H}_{2} \mathrm{O}$ Tanah & $5,75 \mathrm{am}$ & $6,00 \mathrm{am}$ & $6,48 \mathrm{am}$ & $6,64 \mathrm{am}$ \\
\hline 2. C-Organik (\%) & $0,26 \mathrm{sr}$ & $0,17 \mathrm{sr}$ & $0,07 \mathrm{sr}$ & $0,12 \mathrm{sr}$ \\
\hline 3. Nitrogen-Total (\%) & $0,03 \mathrm{sr}$ & $0,02 \mathrm{sr}$ & $0,02 \mathrm{sr}$ & $0,03 \mathrm{sr}$ \\
\hline 4. $\mathrm{C} / \mathrm{N}$ Ratio & $8,67 r$ & $8,50 r$ & $3,50 \mathrm{sr}$ & $4,00 \mathrm{sr}$ \\
\hline 5. $\quad$ P-Tersedia & $4,80 r$ & $5,60 \mathrm{r}$ & $8,10 \mathrm{sr}$ & $9,70 \mathrm{sr}$ \\
\hline 6. $\quad \mathrm{K}-\mathrm{dd}$ & $0,31 \mathrm{r}$ & $0,24 r$ & $0,28 r$ & $0,29 \mathrm{r}$ \\
\hline 7. $\quad$ Ca-dd & $0,050 \mathrm{sr}$ & $0,027 \mathrm{sr}$ & $0,037 \mathrm{sr}$ & $0,025 \mathrm{sr}$ \\
\hline 8. $\quad$ Mg-dd & $0,09 \mathrm{sr}$ & $0,11 \mathrm{sr}$ & $0,17 \mathrm{sr}$ & $0,10 \mathrm{sr}$ \\
\hline 9. $\mathrm{Na-dd}$ & $1,17 \mathrm{t}$ & $0,08 \mathrm{t}$ & $1,19 \mathrm{st}$ & $0,49 \mathrm{st}$ \\
\hline 10. KTK Tanah $(\mathrm{cmol} / \mathrm{kg})$ & $1,39 \mathrm{sr}$ & $2,06 \mathrm{sr}$ & $1,31 \mathrm{sr}$ & $2,11 \mathrm{sr}$ \\
\hline 11. Kejenuhan Aluminium (\%) & $89,41 \mathrm{st}$ & 91,39 st & $82,99 \mathrm{st}$ & 80,25 st \\
\hline 12. Kejenuhan Basa (\%) & $40,29 r$ & $22,18 \mathrm{r}$ & $51,68 \mathrm{~s}$ & $42,89 \mathrm{~s}$ \\
\hline
\end{tabular}

Keterangan: am=agak masam; sr=sangat rendah;

$\mathrm{r}=$ rendah; $\mathrm{t}=$ tinggi; $\mathrm{st}=$ sangat tinggi;

Penambangan emas yang ada di daratan didekat sungai ini menimbulkan masalah. Suryani (2011) mengemukakan bahwa masalah yang dapat ditimbulkan yaitu kerusakan tanah adalah hilangnya topsoil atau menurunnya fungsi tanah, baik sebagai sumber unsur hara tumbuhan maupun sebagai matriks tempat akar tumbuhan berjangkar dan tempat air tersimpan. Penambangan emas di sungai dapat diduga sebagai penyebab rusaknya struktur tanah baik di lapisan atas maupun lapisan bawah. Akibat penambangan ini mengakibatkan terjadinya pengikisan terhadap humus tanah, yaitu lapisan teratas dari permukaan tanah yang mengandung bahan organik, unsur hara yang merupakan tempat tumbuhnya tanaman sehingga menjadi subur.

Berdasarkan data Tabel 3 menunjukan bahwa kandungan $\mathrm{Na}$-dd pada semua lokasi lahan bekas tambang memiliki kriteria tinggi sampai sangat tinggi. Kondisi ini lah yang dapat menyumbangkan nilai kejenuhan basa pada lahan bekas tambang emas tanpa izin memiliki nilai kesuburan tanah rendah sampai dengan sedang. $\mathrm{pH} \mathrm{H}_{2} \mathrm{O}$ tanah di setiap lokasi lahan bekas PETI agak masam, sedangkan parameter C-Organik, Nitrogen-Total, Ca-dd, Mg-dd dan KTK tanah memiliki kriteria sangat rendah. Hal ini menjadikan tanah lahan bekas PETI di beberapa kecamatan Kabupaten Kuantan Singingi kesuburan rendah.

Hasil penelitian yang sama pada lahan bekas tambang emas PETI di Kecamatam Mandor Kabupaten Landak Kalimantan Barat yang dilakukan oleh Yonal et al., (2017) menunjukkan bahwa tanah pada pasca PETI umur 7 dan 20 tahun kandungan KTK sangat rendah, bereaksi masam. Status kesuburan tanah dengan metode pusat penelitian tanah (2009) yaitu, lahan pasca PETI 7 dan 20 tahun status kesuburan sangat rendah.

Hasil penelitian yang sama yang telah dilakukan oleh beberapa peneliti sebelumnya, namun dilakukan pada lahan bekas tambang yang berbeda yaitu pada lahan bekas tambang timah menunjukan hasil yang juga sama bahwa pada Lahan bekas tambang timah tanah mengandung bahan organik sangat rendah, sehingga KTK tanah yang dihasilkan sangat rendah (Pratiwi et al., 2012). Kandungan $\mathrm{C}$ organik dan KTK yang sangat rendah pada lahan bekas tambang timah merupakan indikasi buruknya sifat kimia tanah bekas tambang timah (Asmarhansyah, 2015; Santi 2005; Subardja et al. 2012). Selain itu, nilai $\mathrm{pH}$ tanah dan kandungan unsur hara makro esensial juga tergolong sangat rendah. Asmarhansyah (2015) melaporkan bahwa lahan bekas tambang emas memiliki kandungan bahan organik sangat rendah, total $\mathrm{N}, \mathrm{P} 2 \mathrm{O} 5, \mathrm{~K} 2 \mathrm{O}$, dan basa-basa dapat ditukar $(\mathrm{Ca}, \mathrm{Mg}, \mathrm{K}$, dan $\mathrm{Na}$ ) termasuk sangat rendah sampai rendah.

\section{Kandungan Total Mikroba Tanah Bekas Tambang Emas Tanpa Izin}

Berdasarkan hasil pengamatan terhadap total mikrob tanah bekas tambang emas tanpa izin (Tabel 4) menunjukan bahwa pada Kecamatan Sentoja Raya dan Kecamatan Logas Tanah Darat total mikrob tanah jauh lebih tinggi dibandingkan dengan Kecamatan Singingi dan Kecamatan Kuantan Tengah. Hal ini erat kaitannya dengan $\mathrm{pH}$ tanah bekas tambang emas (Tabel 3). 
Tabel 4. Kandungan total mikroba tanah bekas tambang emas

\begin{tabular}{lc}
\hline \multicolumn{1}{c}{ Lokasi Pengamatan } & Total Bakteri CFU/g \\
\hline Kec. Singingi & $4,00 \times 10^{6}$ \\
Kec. Kuantan Tengah & $3,91 \times 10^{6}$ \\
Kec. Sentoja Raya & $1,50 \times 10^{7}$ \\
Kec. Logas Tanah Darat & $1,09 \times 10^{\prime}$ \\
\hline
\end{tabular}

Menurut Anisa (2010) populasi mikrob dan fungi tanah sangat dipengaruhi oleh kadar air, banyaknya bahan makanan yang tersedia, suhu tanah, kedalaman lapisan tanah. Pada umumnya mikrob dan fungi tanah lebih menyukai $\mathrm{pH}$ berkisar netral (5.5-6.5) dan dapat tumbuh pada $\mathrm{pH}$ masam maupun alkalin tetapi tidak optimal.

Jika dibandingkan antara total mikrob tanah yang subur dengan tanah bekas tambang emas, maka total mikrob dilahan bekas tambang emas jauh lebih rendah. Menurut Purwaningsih (2009) bahwa tanah yang subur mengandung $>100$ juta mikroorganisme per gram tanah. Rendahnya total mikrob pada lahan bekas tambang emas disebabkan karena kegiatan penambangan mengakibatkan terkikisnya lapisan topsoil dan serasah sebagai sumber karbon untuk menyokong kelangsungan hidup mikroba tanah potensial. Hal ini merupakan salah satu penyebab utama menurunnya populasi dan aktifitas mikroba tanah.

Selain itu, berbagai faktor lingkungan seperti penurunan $\mathrm{pH}$, kelembaban tanah, kandungan bahan organik, daya pegang tanah terhadap air dan struktur tanah menyebabkan rendahnya aktifitas mikroba tanah. Mikroba tanah mempunyai fungsi penting dalam penyediaan unsur-unsur hara untuk kelangsungan hidup tanaman. Soebowo (2011) mengatakan bahwa populasi hayati tanah yang ada di tanah lapisan atas menjadi terbenam, sehingga hilang atau mati dan tidak berfungsi sebagaimana mestinya.

\section{KESIMPULAN}

Berdasarkan hasil penelitian dapat disimpulkan bahwa:

1. Kecamatan Singingi, Kecamatan Kuantan Tengah, Kecamatan Sentoja Raya dan Kecamatan Logas Tanah Darat memiliki tekstur tanah pasir berlempung sampai pasir

2. Kecamatan Singingi, Kecamatan Kuantan Tengah, Kecamatan Sentoja Raya dan Kecamatan Logas Tanah Darat memiliki kandungan $\mathrm{pH} \mathrm{H}_{2} \mathrm{O}$ 5.75-6.64 tergolong sangat masam, C-Organic $0.07-0.26 \%$, Ca-dd $0.025-0.050$ me/100g, NitrogenTotal $\quad 0.02-0.03 \%, \quad$ Mg-dd 0.09-0.17 $\mathrm{me} / 100 \mathrm{~g}$, dan KTK $1.39-2.11 \mathrm{me} / 100 \mathrm{~g}$ dengan kriteria kesuburan sangat rendah, $\mathrm{C} / \mathrm{N}$ Ratio 3.50-8.67 dengan kriteria kesuburan rendah sampai sangat rendah, kandungan K-dd $\quad 0.24-0.31 \mathrm{me} / 100 \mathrm{~g}$ dengan kriteria rendah, Na-dd 0.08-1.19 me/100g dengan kriteria sedang sampai dengan sangat tinggi, kejenuhan aluminium sangat tinggi dengan kejenuhan basa kriteria kesuburan rendah.

3. Total mikrob pada kecamatan Sentoja Raya dan Kecamatan Logas Tanah Darat jauh lebih tinggi dibandingkan Kecamatan Singingi dan Kecamatan Kuantan Tengah.

\section{Ucapan Terima Kasih}

Kami sampaikan ucapan terima kasih kepada Lembaga Penelitian dan Pengabdian Masyarakat (LPPM) Universitas Islam Riau yang telah mendanai proyek penelitian ini dengan kontrak nomor: 617/KONTRAK/LPPM$\mathrm{UIR} / 5-2019$.

\section{DAFTAR PUSTAKA}

Anisa RA. Hubungan Morfologi Tanah Bekas Tambang Batubara dengan Beberapa Sifat Kimia, Fisik, dan Biologi Tanah Di Pt. Kaltim Prima Coal. Skripsi Institut Pertanian Bogor.

Asmarhansyah. 2015. Characteristics of Physical and Chemical Properties of Former-Tin Mining Areas for Crop Production in Bangka Island. Prosiding. Nasional Sistem Informasi dan Pemetaan Sumberdaya Lahan Mendukung Swasembada Pangan. Balai Besar Penelitian dan Pengembangan Sumberdaya Lahan Pertanian. Bogor.

[Balit Tanah] Balai Penelitian Tanah. 2006. Sifat Fisik Tanah dan Metode Analisisnya. Balai Penelitian Tanah, Badan Penelitian dan Pengembangan Pertanian, Departemen Pertanian, Bogor.

[Balit Tanah] Balai Penelitian Tanah. 2009. Petunjuk Teknis Analisis Kimia Tanah, Tanaman, Air, dan Pupuk. Balai Penelitian Tanah, Badan Penelitian dan Pengembangan Pertanian, Departemen Pertanian, Bogor. 
Hardjowigeno, S. 2003. Klasifikasi Tanah dan Pedogenesis. Akademika Pressindo. Jakarta.

Hastuti RD, Ginting RCB. 2007. Enumerasi bakteri, cendawan dan aktinomicetes. Di dalam : Saraswati R, Husen E, Simanugkalit RMD, editor. Metode Analisis Biologi Tanah. Bogor (ID): Balai Besar Penelitian dan Pengembangan Sumberdaya Lahan, Badan Penelitian dan Pengembangan.

Maryani IS. 2007. Dampak Penambangan Pasir pada Lahan Hutan Alam terhadap Sifat Fisik, Kimia, dan Biologi Tanah (Studi Kasus: Di Pulau Sebaik Kabupaten Kepulauan Riau [skripsi]. Bogor (ID): Institut Pertanian Bogor.

Mulyani, S. 2018. Pemetaan Lokasi Lahan Bekas Pertambangan Emas Tanpa Izin (PETI) pada Beberapa Kecamatan di Kabupaten Kuantan Singingi. Laporan Hasil Penelitian Universitas Islam Riau.

Napitupulu D. 2012. Dinamika populasi mikrob tanah dengan sistem pola tanam padi kedelai pada pertanian organik [tesis]. Bogor (ID): Institut Pertanian Bogor.

Nasution. 2003. Teknik Sampling. http://library.usu.ac.id/download/fkm/fkm rozaini.pdf. Diakses tanggal 16 April 2018.

Nuraini, Linda, R dan Gusrizal. 2014. Pengkayaan Tanah Bekas Tambang Emas Dengan Penambahan Lumpur IPAM Sebagai Media Pertumbuhan Sawi (Brassica juncea L.). Jurnal Protobiont Vol 3 (2): 135 - 140.

Pratiwi, Santoso, E. dan Turjaman, M. 2012. Penentuan dosis bahan pembenah tanah (ameliorant) untuk perbaikan tanah dari tailing kuarsa sebagai Medium tumbuh tanaman hutan. Jurnal Penelitian Hutan dan Konservasi Alam. Vol 9 (2):163-174.

Purwaningsih S. 2009. Populasi bakteri Rhizobium di tanah pada beberapa tanaman dari Pulau Buton, Kabupaten Muna, Provinsi Sulawesi Tenggara. Jurnal Tanah Trop 14 (1): 65-70.

Putra, C.A.S . 2010. Evaluasi Revegetasi Lahan Bekas Tambang Emas PT. Newmont Minahasa Raya, Manado, Sulawesi Utara [skripsi]. Bogor (ID): Institut Pertanian Bogor.

Santi, R. 2005. Pertumbuhan Nilam (Pogostemon cablin Benth) pada sandy tailing asal lahan pasca penambangan timah yang diberi kompos dan tanah kupasan (overburden). Thesis. Program
Studi IImu Tanaman Program Pascasarjana Universitas Sriwijaya

Soebowo G., 2011, Penambangan Sistem Terbuka Ramah Lingkungan dan Upaya Reklamasi Pasca Tambang untuk Memperbaiki Kualitas Sumberdaya Lahan dan Hayati Tanah, Jurnal Sumberdaya Lahan, Volume 5 Nomor 2, Desember 2011.

Subardja, A. Kasno, dan Sutono. 2012. Teknologi Pencetakan Sawah pada Lahan Bekas Tambang Timah di Bangka Belitung. Prosiding. Seminar Nasional Teknologi Pemupukan dan Pemulihan Lahan Terdegradasi. Hal. 111-122. Penyunting: Wigena et al. Bogor, 29-30 Juni 2012. Badan Penelitian dan Pengembangan Pertanian, Kementerian Pertanian. 2012.

Suryani, I. 2011. Dinamika Sifat Fisik Tanah Pada Areal Pertanaman Kakao AkibatAlih Guna Lahan Hutan Di Kecamatan Papalang Kabupaten Mamuju. Jurusan Kahutanan UNHAS Makasar. Hal 2-3.

Widyastuti R, Anas I. 2013. Petunjuk Laboratorium Biologi dalam Praktek. Bogor (ID): Direktorat Jenderal Pendidikan Tinggi, Pusat Antara Universitas Bioteknologi, Institut Pertanian Bogor.

Widyati E. 2008. Peranan Mikroba Tanah pada Kegiatan Rehabilitasi Lahan Bekas Tambang. J. Info Hutan 5(2): 151-160.

Yonal P, Sulakhudin S, dan Hayati R. 2017. Kajian Kesuburan Tanah di Lahan Pasca Penambangan Emas Tanpa Izin (PETI) pada Beberapa Periode Penambangan di Kecamatan Mandor Kabupaten Landak. J. Sains Mahasiswa Pertanian, Vol 6 (2). 
Analisis Tekstur, Kandungan Unsur Hara dan Total Mikroba Tanah Bekas PETI (Mulyani, et al.) 